\title{
A Fluorescence Active Catalyst Support Comprising Carbon Quantum Dots and Magnesium Oxide Doping for Stabilization of Palladium Nanoparticles: Application as a Recoverable Catalyst for Suzuki Reaction in Water
}

$$
\text { Mohammad Gholinejad }^{a}{ }^{*}, \text { Maedeh Bahrami }{ }^{a} \text {, Carmen Nájera }^{b, *}
$$

${ }^{a}$ Department of Chemistry, Institute for Advanced Studies in Basic Sciences (IASBS), P. O. Box 5195-1159, Gava zang, Zanjan 45137-6731, Iran. Email: gholinejad@iasbs.ac.ir; ${ }^{\mathrm{b}}$ Departamento de Química Orgánica and Centro de Innovación en Química Avanzada (ORFEO-CINQA).

Universidad de Alicante, Apdo. 99, E-03080-Alicante, Spain. Email: cnajera@ua.es

\begin{abstract}
Novel magnesium oxide-carbon quantum dots have been synthesized and used for the formation and stabilization of palladium nanoparticles. This highly water dispersible material, Pd@MgO-CQD, has been used as an active catalyst for Suzuki coupling of aryl bromides at room temperature and aryl chlorides at $80{ }^{\circ} \mathrm{C}$ in water. Using fluorescence emission of the material, a new protocol for determine of Pd loading and leaching in catalyst preparation and recycling process was developed.
\end{abstract}

Keywords: MgO, Carbon, Quantum dots, Fluorescence, Palladium, Suzuki 


\section{Introduction}

Environmental problems rose up from chemical progression encouraged chemists for designing new methodologies matched with green chemistry objectives [1-7]. For instance industries have started employing green chemistry practices such as waste prevention by designing high performance heterogeneous catalysts based on naturally available materials and the use of less

toxic solvents and reagents. ${ }^{8-11}$ Palladium catalyzed cross-coupling reactions are important approaches for the formation of carbon-carbon and carbon-heteroatom bonds [12-18]. In recent years, because of high toxicity and price of palladium, growing interest has been paid to development of different heterogeneous palladium catalysts [19-22]. Magnesium oxide and clay minerals with high surface area can be found widely in nature and have been used as catalysts or as supports for stabilization of transition metal catalysts [23-27]. Rao and coworkers prepared water dispersible sheets of Mg-phyllo(organo)silicates containing pendant amino ligands and used it for stabilization of Au, Ag, Pd, and Pt nanoparticles [28]. Also, very recently we reported clay composite carrying phosphinite-functionalized ionic liquid moieties (CCPIL) for palladium nanoparticles stabilization and their applications in different coupling reactions [29].

Carbon quantum dots (CQD) are nanomaterials with excellent water solubility, strong fluorescence emission, high photostability, non-toxicity, and good biocompatibility. In past few years, CQD have been used in different applications such as biomedicine delivery systems, biosensors, dye-sensitized solar cells, organic solar cells, supercapacitors, light-emitting devices, and photocatalysts [30-32]. Recently, CQD have been used for reduction of palladium salt, formation of palladium nanoparticles and applied as an efficient catalyst in Suzuki and Heck coupling reactions [33]. Very recently, we have also reported modification of $\mathrm{Fe}_{3} \mathrm{O}_{4}$ nanoparticles with CQD and its application for the stabilization of palladium nanoparticles in the 
Suzuki reaction [34]. Despite the high efficiency of our reported catalyst, quenching of fluorescence in CQD@ $\mathrm{Fe}_{3} \mathrm{O}_{4}$ NPs is the drawback of this material. For instance, this problem prohibited further application of the material in fluorescence active reactions. Herein, we wish to report novel MgO-CQD as a fluorescence active composite for formation and stabilization of PdNPs (referred as Pd@MgO-CQD throughout the text of this article) and its application as highly dispersible catalyst in very mild Suzuki reaction of aryl bromides and chlorides in water.

\section{Material and methods}

\subsection{Synthesis of MgO-CQD}

To a stirring solution of polyethylene glycol $200(25 \mathrm{~mL})$, was added $\mathrm{Mg}\left(\mathrm{NO}_{3}\right)_{2}(9 \mathrm{~g})$ and the mixture was stirred at room temperature until the salt was completely dissolved. To the resulting mixture, an aqueous solution of $\mathrm{Na}_{2} \mathrm{CO}_{3}(1.2 \mathrm{~g})$ and urea $(1.2 \mathrm{~g})$ in water $(8 \mathrm{~mL})$ was added and the resulting mixture was sonicated for $30 \mathrm{~min}$ and then was heated in autoclave at $160{ }^{\circ} \mathrm{C}$ for 2 h. Then, the mixture was cold down to room temperature and obtained solid was centrifuged and dried in the oven affording $5.2 \mathrm{~g}$ fluorescence active MgO-CQD.

\subsection{Synthesis of Pd@MgO-CQD}

MgO-CQD (1 g) was added to a stirring 1:1 mixture of $\mathrm{H}_{2} \mathrm{O}$ and EtOH (5 mL). Then, sonicated solution of $\mathrm{PdCl}_{2}(40 \mathrm{mg}, 0.22 \mathrm{mmol})$ in $\mathrm{H}_{2} \mathrm{O}(3 \mathrm{~mL})$ was added under argon atmosphere and stirred at $60{ }^{\circ} \mathrm{C}$ for $24 \mathrm{~h}$. The resulting suspension was centrifuged and the solid was filtered off. After drying in the oven for $24 \mathrm{~h}$ at $80{ }^{\circ} \mathrm{C}, 0.93 \mathrm{~g}$ of Pd@MgO-CQD containing $0.148 \mathrm{mmolg}^{-1}$ palladium was obtained.

\subsection{General procedure for Suzuki-Miyaura reaction.}


Pd@MgO-CQD catalyst (10 mg, 0.3 mol\%), aryl halide (0.5 mmol), arylboronic acid (0.75 mmol), $\mathrm{K}_{2} \mathrm{CO}_{3}$ (103 mg, $1 \mathrm{mmol}$ ), and distilled $\mathrm{H}_{2} \mathrm{O}(2 \mathrm{~mL}$ ) were added to a flask and the mixture was stirred at $30{ }^{\circ} \mathrm{C}$ for aryl bromides and at $80{ }^{\circ} \mathrm{C}$ for aryl chlorides. After completion of the reaction, which was monitored by GC, crude products were extracted by EtOAc $(2 \times 5 \mathrm{~mL})$ and purified using column chromatography.

2.4.Typical recycling procedure for the reaction between 4-bromobenzonitrile and phenylboronic acid.

After completion of the reaction (monitored by GC), the resulting reaction mixture was extracted with ethyl acetate $(3 \times 4 \mathrm{~mL})$, the organic phase was dried and the product was purified using column chromatography. Then, the residue was subjected to centrifugation (6000 rpm) for 10 min and the solid catalyst was separated which was washed with diethyl ether and dried for further use in another batch.

\section{Results and discussion}

In a typical preparation, Pd@MgO-CQD was prepared using reaction of $\operatorname{Mg}\left(\mathrm{NO}_{3}\right)_{2}$, urea and PEG 200 in an autoclave at $160{ }^{\circ} \mathrm{C}$ and obtained CQD was treated with aqueous solution of $\mathrm{PdCl}_{2}$ at room temperature. The as-synthesized Pd@MgO-CQD characterized by fluorescence spectroscopy, X-ray photoelectron spectroscopy (XPS), inductively coupled plasma (ICP), transmission electron microscopy (TEM), scanning electron microscopy combined with electron dispersive spectrometry and elemental mapping (SEM-EDS, SEM-map).

Loading of Pd on MgO-CQD was determined by ICP analysis to be $0.148 \mathrm{mmolg}^{-1}$. Comparing fluorescence intensity of MgO-CQD with obtained Pd@MgO-CQD showed decreasing of 
fluorescence emission in Pd@MgO-CQD. This decreasing can be attributed to the electron transfer from the CQD to metallic ions [35-36].

In order to find an exact correlation between amount of loaded Pd and fluorescence intensity, different Pd@MgO-CQD samples with different loading of Pd were prepared and fluorescence emissions were studied. Results of our study indicated decreasing of fluorescence intensity with increasing of palladium loading on MgO-CQD (Fig. 1). As it shown in Fig. 2, using palladium and fluorescence emission values, a linear equation between factor X (mmol of supported $\mathrm{Pd}$ ) and factor Y (fluorescence intensity) was obtained. This equation showed good harmony between content of supported Pd and emission and it is possible to find amount of Pd on support in each stage of catalytic reaction.

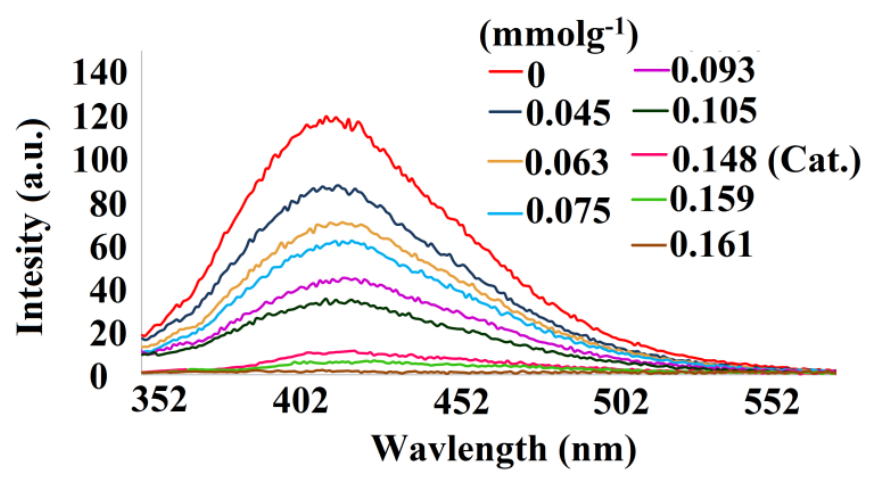

Fig. 1. Fluorescence emissions of Pd@MgO-CQD with different Pd loadings 


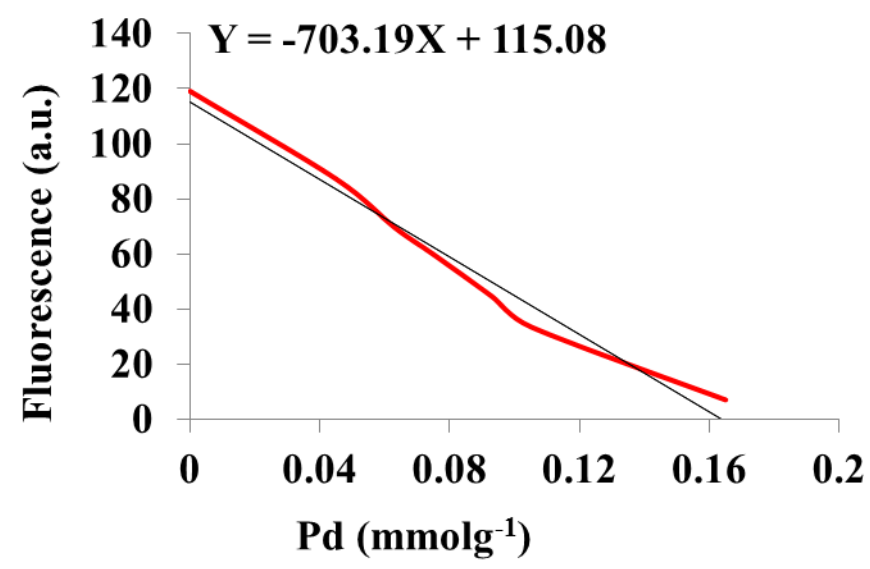

Fig. 2. A linear equation between amount of supported Pd and fluorescence intensity

Presence of carbon in the structure of Pd@MgO-CQD was confirmed by X-ray photoelectron spectroscopy (XPS) study of C1s region. Results showed related peaks to C-C or C=C, C-N, C$\mathrm{O}-\mathrm{C}$ and $\mathrm{O}-\mathrm{C}=\mathrm{O}$ forms of carbon in 284.7, 285.4, 286.1, and $288.7 \mathrm{eV}$ which are characteristic for carbon in CQDs (Fig. 3) [37-38].

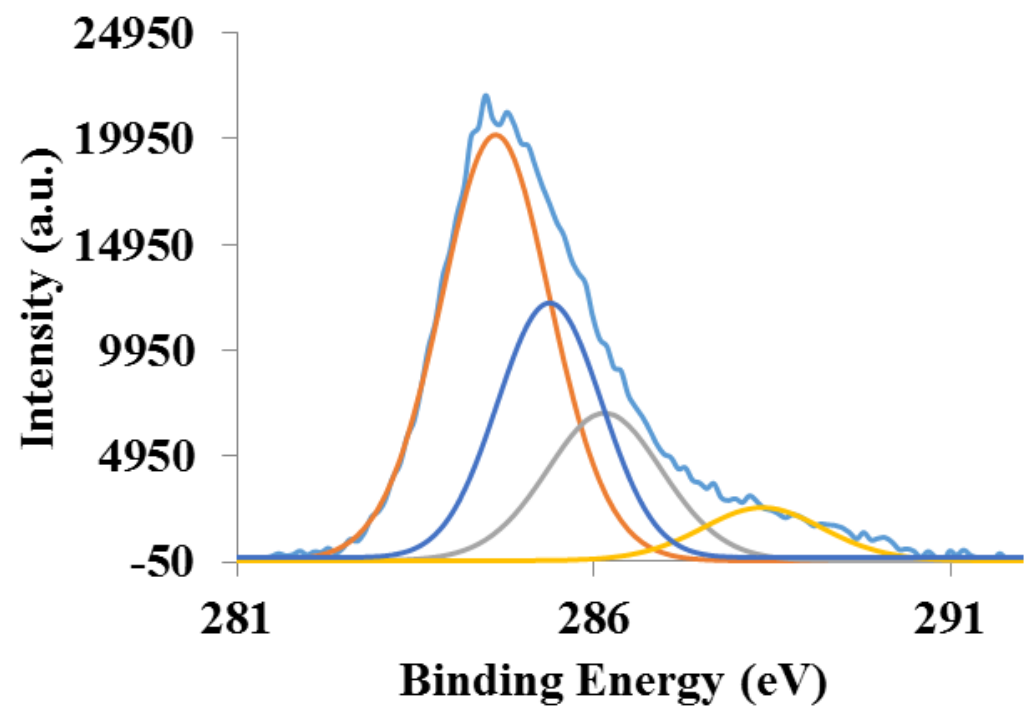

Fig. 3. XPS spectrum of Pd@MgO-CQD in the C1s region. 
Also, XPS spectrum of the region corresponding to the binding energy range of 335-342 eV related to $P d 3 d_{5 / 2}$ and $P d 3 d_{3 / 2}$ was studied. Results indicated the presence of two intensive doublets at 335.5 and $340.7 \mathrm{eV}$ related to $\mathrm{Pd}(0)$ and peaks at 337 and $342.5 \mathrm{eV}$ related to $\mathrm{Pd}(\mathrm{II})$ species.[39-41]. These results indicate that $46 \%$ of palladium exist in $\operatorname{Pd}(0)$ state confirming the reducing ability of MgO-CQD (Fig. 4).

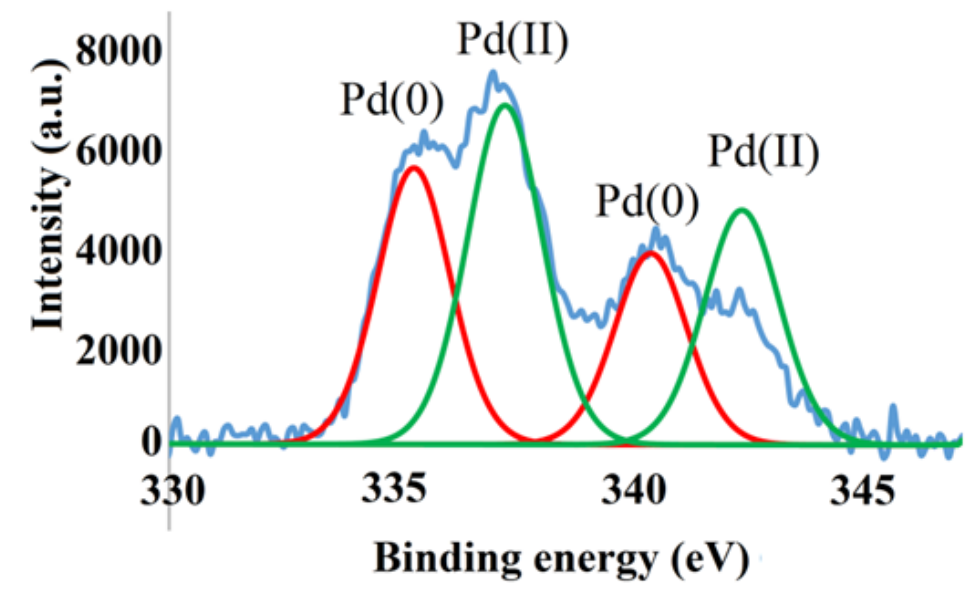

Fig. 4. XPS spectrum of Pd@ MgO-CQD in the Pd3d region.

Furthermore, XPS study for Mg1s region showed a single peak in position of $1304 \mathrm{eV}$ which fits well with MgO structure (Fig. 5) [42].

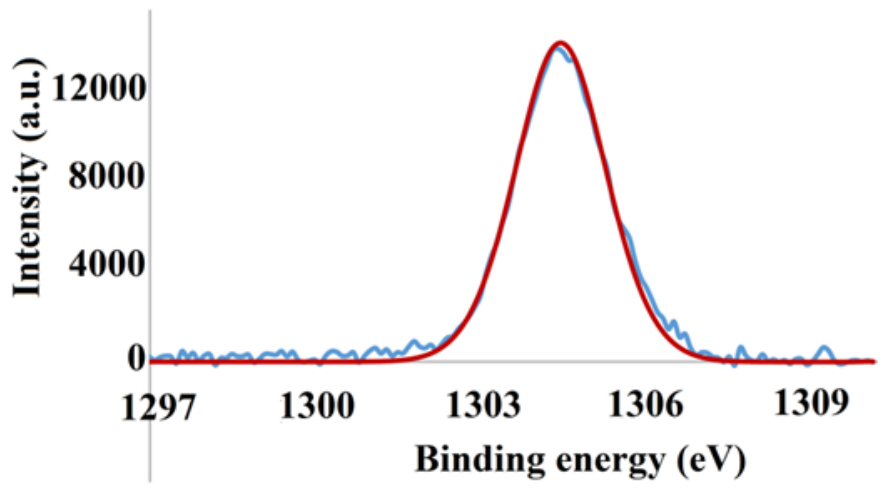


Fig. 5. XPS spectrum of Pd@ MgO-CQD in the Mg1s region.

In order to study elemental distribution of the Pd@MgO-CQD, elemental mapping was studied and results confirmed presences of $\mathrm{C}, \mathrm{Pd}$, and $\mathrm{Mg}$ in the structure (Fig. 6a-c). These results was further confirmed using SEM-EDX and showed the presence of the mentioned elements in the structure (Fig. 6d).

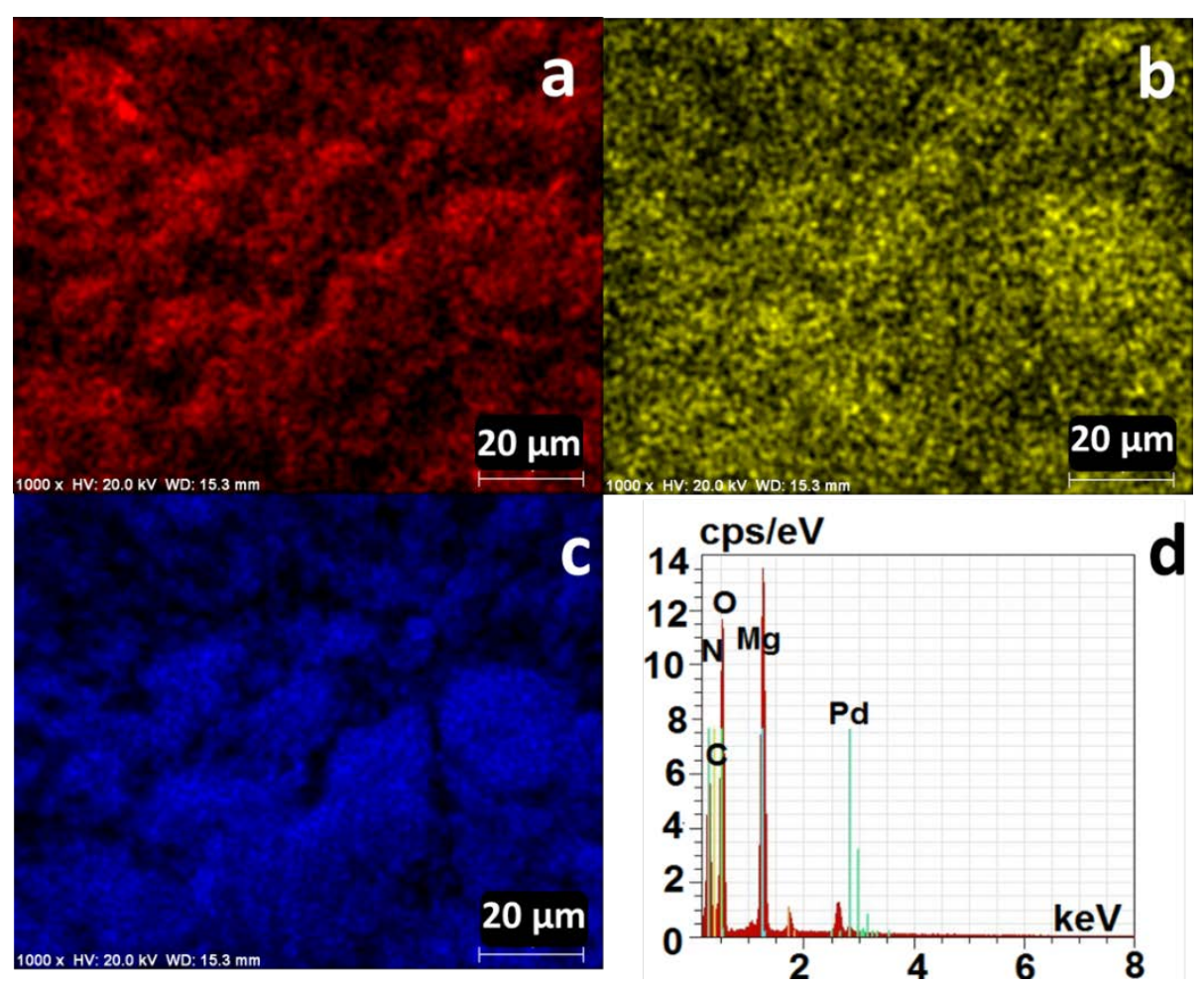

Fig. 6. EDX elemental mapping of (a) C, (b) Pd, and (c) Mg. (d) EDX-SEM of Pd@MgO-CQD

SEM images of the Pd@MgO-CQD in different magnification showed the formation of MgOCQD sheets as well as appearance of palladium particles (bright dots) in the surface (Fig. 7). Also, TEM images of Pd@MgO-CQD in different magnification indicate the presence of highly 
mono-dispersed and uniform palladium NPs in 2-6 nanometer size in the structure of MgO-CQD (Fig. 8).

The nitrogen adsorption-desorption isotherms for Pd@ MgO-CQD is matched with type III adsorption isotherm confirming formation of multi-layer structure of the material matching well with MgO structure ${ }^{43}$ (Fig. 1, ESI).

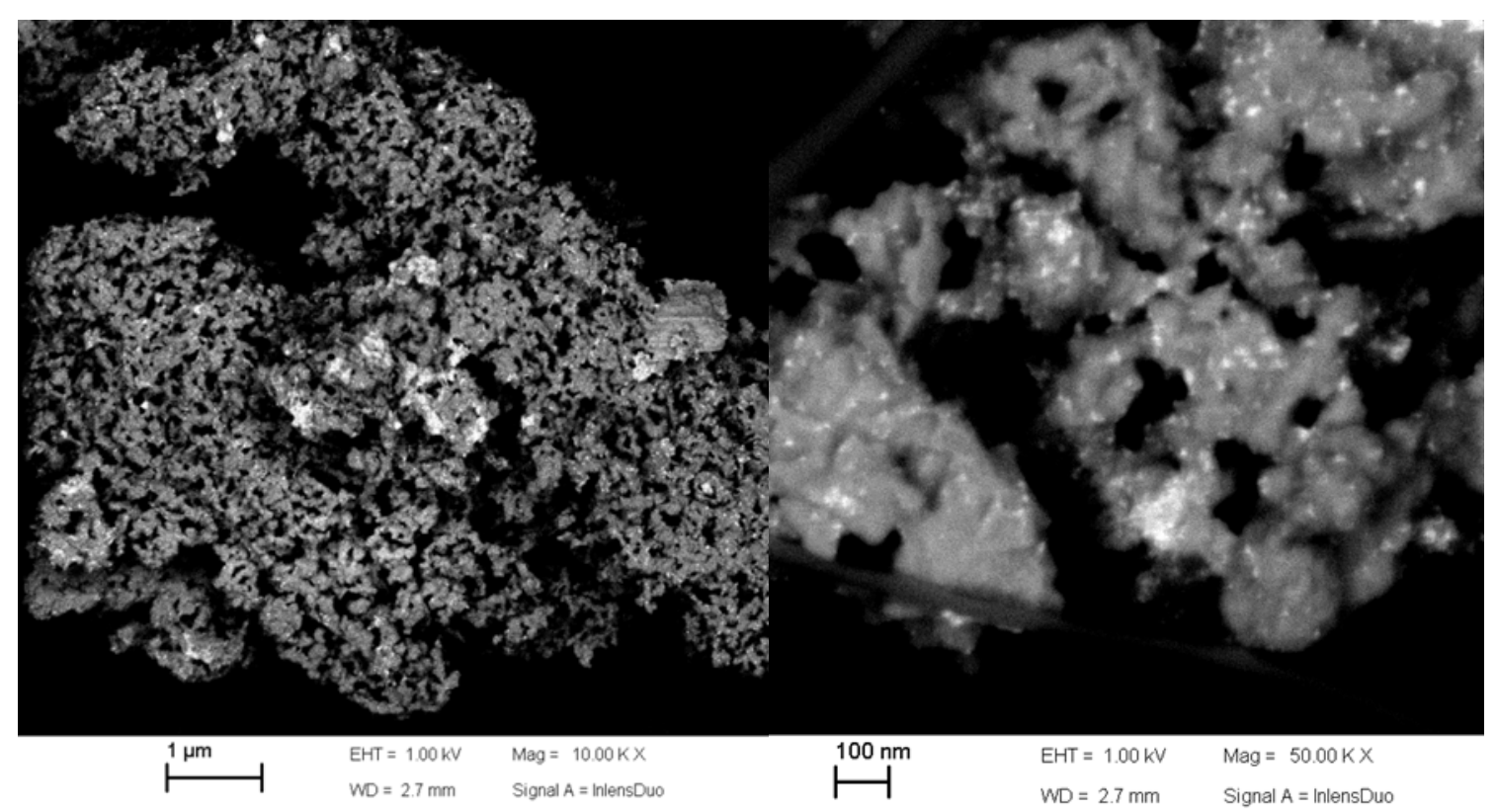

Fig.7. SEM images of Pd@MgO-CQD. 


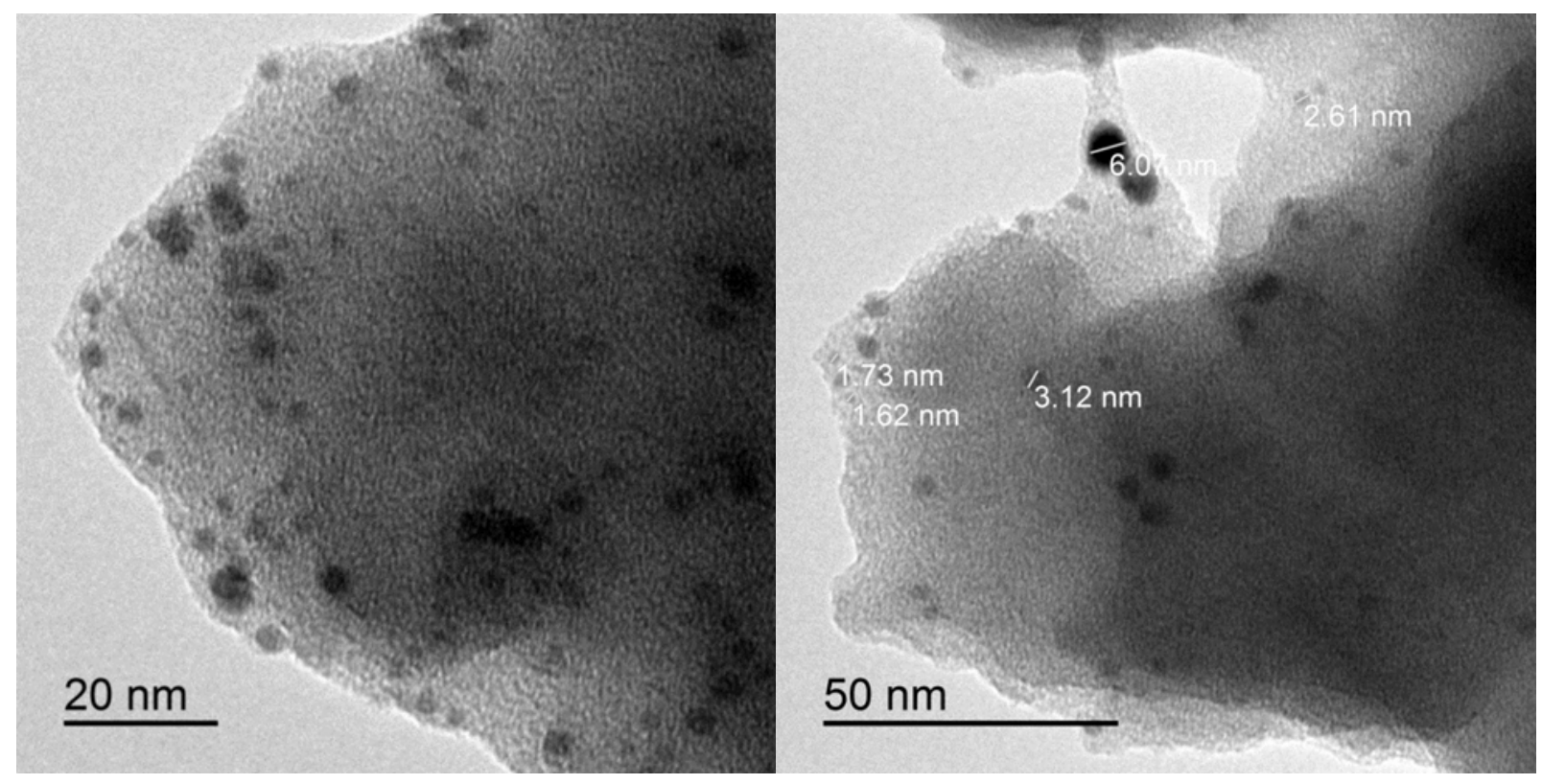

Fig. 8. TEM images of Pd@MgO-CQD

The catalytic activity of prepared Pd@MgO-CQD was assessed in the Suzuki-Miyaura coupling reaction. Initially, reaction of 4-bromoanisol with phenylboronic acid in water was selected as a benchmark reaction and the effect of different bases and temperatures was studied (Table 1). Results indicate that using $0.4 \mathrm{~mol} \%$ of catalyst and different bases such as $t$-BuOK, $\mathrm{K}_{2} \mathrm{CO}_{3}$, $\mathrm{Et}_{3} \mathrm{~N}$, and $\mathrm{NaOH}$ at $80{ }^{\circ} \mathrm{C}$ reactions proceed almost efficiently giving yields in the range of 10 99\% (Table 1, entries 1-4). When the reaction temperature was decreased to $50{ }^{\circ} \mathrm{C}$ the best yield was obtained using $\mathrm{K}_{2} \mathrm{CO}_{3}$ as base (Table 1, entries 5-7). By lowering the reaction temperature to $30{ }^{\circ} \mathrm{C}$ and using 0.3 or $0.4 \mathrm{~mol} \%$ of $\mathrm{Pd}$ and $\mathrm{K}_{2} \mathrm{CO}_{3}$ as a base, excellent GC yields were obtained (Table 1, entries 8-9). However, by decreasing the Pd amount to 0.2 and $0.1 \mathrm{~mol} \%$ lower yields (68-90\%) were observed (Table 1 , entry 10-11). Therefore, we selected 0.3 mol\% of Pd catalyst, $\mathrm{K}_{2} \mathrm{CO}_{3}$ as base at $30^{\circ} \mathrm{C}$, as the most efficient reaction conditions to study the scope of this crosscoupling reaction (Table 1,entry 8). 
Table 1. Optimization of the reaction conditions for the reaction of 4-bromoanisol and phenylboronic acid ${ }^{\mathrm{a}}$

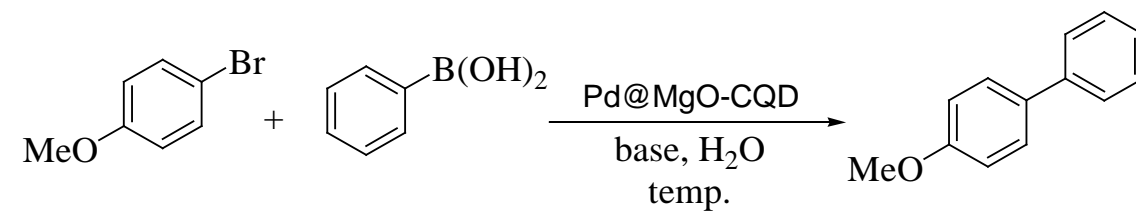

\begin{tabular}{|c|c|c|c|c|c|}
\hline Entry & Base & $\mathrm{T}\left({ }^{\circ} \mathrm{C}\right)$ & Time (h) & $\mathrm{Pd}$ mol\% & Yield $^{\mathrm{b}}(\%)$ \\
\hline 1 & $t$-BuOK & 80 & 6 & 0.4 & 10 \\
\hline 2 & $\mathrm{~K}_{2} \mathrm{CO}_{3}$ & 80 & 6 & 0.4 & 99 \\
\hline 3 & $\mathrm{Et}_{3} \mathrm{~N}$ & 80 & 6 & 0.4 & 90 \\
\hline 4 & $\mathrm{NaOH}$ & 80 & 6 & 0.4 & 98 \\
\hline 5 & $\mathrm{~K}_{2} \mathrm{CO}_{3}$ & 50 & 6 & 0.4 & 96 \\
\hline 6 & $\mathrm{NaOH}$ & 50 & 6 & 0.4 & 68 \\
\hline 7 & $\mathrm{Et}_{3} \mathrm{~N}$ & 50 & 6 & 0.4 & 56 \\
\hline 8 & $\mathrm{~K}_{2} \mathrm{CO}_{3}$ & 30 & 9 & 0.4 & 98 \\
\hline 9 & $\mathrm{~K}_{2} \mathrm{CO}_{3}$ & 30 & 9 & 0.3 & 97 \\
\hline 10 & $\mathrm{~K}_{2} \mathrm{CO}_{3}$ & 30 & 9 & 0.2 & 90 \\
\hline 11 & $\mathrm{~K}_{2} \mathrm{CO}_{3}$ & 30 & 9 & 0.1 & 68 \\
\hline
\end{tabular}

${ }^{\mathrm{a}}$ Reactions performed on a $0.5 \mathrm{mmol}$ scale. ${ }^{\mathrm{b}}$ GC yields. 
Having optimized conditions in hand, reactions of structurally different aryl bromides having electron-donating groups such as -OMe and -OH as well as electron-withdrawing groups such as -COMe, - $\mathrm{CN},-\mathrm{NO}_{2},-\mathrm{COH},-\mathrm{Cl}$, and bromobenzene proceed effectively to afford the corresponding biaryls in excellent yields (Table 2, entries 1-7). Reaction of 5-bromoindol as heterocyclic halide also proceed well providing the desired product in 76\% yield (Table 2, entry 8). Furthermore, other arylboronic acids such 3,5-difluorophenylboronic acid, 4methoxyphenylboronic acid, 2-naphtylboronic acid, 4-chlorophenylboronic acid, and 2fluorophenylboronic were reacted efficiently with aryl bromides and afford the corresponding products in high to excellent yields (Table 2, entries 9-16). Studies of reactions of aryl chlorides under optimized reaction conditions afford low yields. However, increasing the reaction temperature to $80{ }^{\circ} \mathrm{C}$, activated 4-chlorobenzonitrile, 4-chloronitrobenzene, 2,4dichloronitrobenzene reacted with arylboronic acids and desired biphenyl products were obtained in 72-98\% isolated yields (Table 2, entries 17-20).

Table 2. Suzuki-Miyaura reaction of structurally different aryl bromides and chlorides with different arylboronic acids catalyzed by Pd@MgO-CQD. ${ }^{\mathrm{a}}$

$$
\mathrm{Ar}^{1} \mathrm{X}+\mathrm{Ar}^{2} \mathrm{~B}(\mathrm{OH})_{2} \underset{\mathrm{K}_{2} \mathrm{CO}_{3}, \mathrm{H}_{2} \mathrm{O}, 30^{\circ} \mathrm{C}}{\stackrel{\mathrm{Pd} @ \mathrm{MgO}-\mathrm{CQD}(0.3 \mathrm{~mol} \%)}{\longrightarrow}} \mathrm{Ar}^{1}-\mathrm{Ar}^{2}
$$

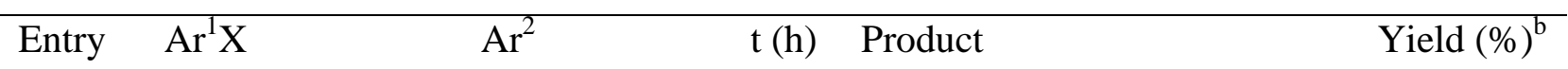




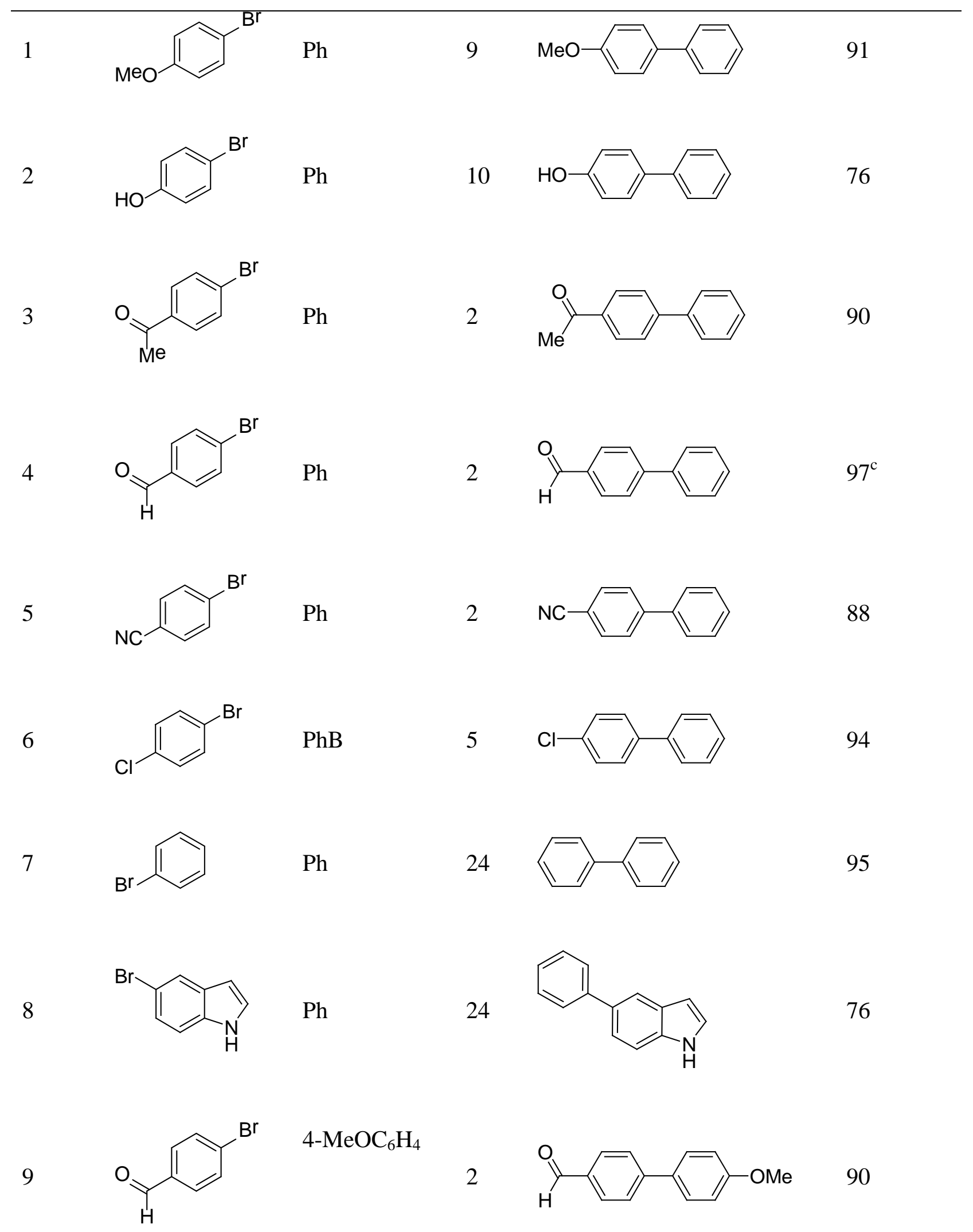


10<smiles>O=Cc1ccc(Br)cc1</smiles>

3,5difluorophenyl

15<smiles>O=Cc1ccc(-c2cc(F)cc(F)c2)cc1</smiles>

3<smiles>N#Cc1ccc(-c2ccc(Cl)cc2)cc1</smiles>

11<smiles>CCC(C)(Cl)[Ge]</smiles>

12<smiles>O=Cc1ccc(Br)cc1</smiles>

2-naphtyl<smiles>Brc1ccccc1</smiles>

14<smiles>Brc1ccccn1</smiles>

15<smiles>COc1ccc(Br)cc1</smiles>

4- $\mathrm{MeOC}_{6} \mathrm{H}_{4}$

24<smiles>O=Cc1ccc(Br)cc1</smiles>

17<smiles>N#Cc1ccc(Cl)cc1</smiles>

$\mathrm{Ph}$
24<smiles>O=Cc1ccc(-c2ccc3ccccc3c2)cc1</smiles>

97<smiles>COc1ccc(-c2ccccc2)cc1</smiles>

16<smiles>O=Cc1ccc(-c2ccccc2F)cc1</smiles>
92 $72^{\mathrm{d}}$ 
<smiles>O=[N+]([O-])c1ccc(Cl)cc1</smiles>

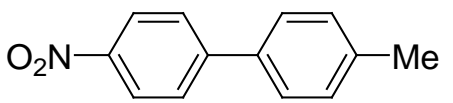

$81^{\mathrm{d}}$

19<smiles>O=[N+]([O-])c1ccc(Cl)c([N+](=O)[O-])c1</smiles>

$\mathrm{Ph}$

24<smiles>O=[N+]([O-])c1ccc(-c2ccccc2)c([N+](=O)[O-])c1</smiles>

$97^{\mathrm{d}}$

20

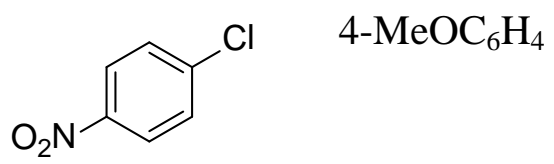

48

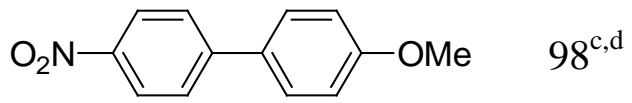

${ }^{\mathrm{a}}$ Reaction conditions: ArX (0.5 mmol), arylboronic acid (0.75 mmol), $\mathrm{K}_{2} \mathrm{CO}_{3}(0.75 \mathrm{mmol}, 103$ mg), $\mathrm{H}_{2} \mathrm{O}$ (1.5 mL), catalyst (12 mg, $\left.0.3 \mathrm{~mol} \% \mathrm{Pd}\right) .{ }^{\mathrm{b}}$ Isolated yields. ${ }^{\mathrm{c}} \mathrm{GC}$ yields. ${ }^{\mathrm{d}}$ Reactions performed in equal ratio of $\mathrm{H}_{2} \mathrm{O}-\mathrm{EtOH}(1.5 \mathrm{~mL})$.

One of the main factors required in designing heterogeneous catalysts, especially for industrial scale reactions is the recyclability of the catalyst. Along this line, we have studied recyclability of the Pd@MgO-CQD for the reaction of 4-bromobenzonitrile and phenylboronic acid under the optimized reaction conditions. Results indicated that catalyst can be recycled for 6 consecutive runs with decreasing in reaction yield (Fig. 9).

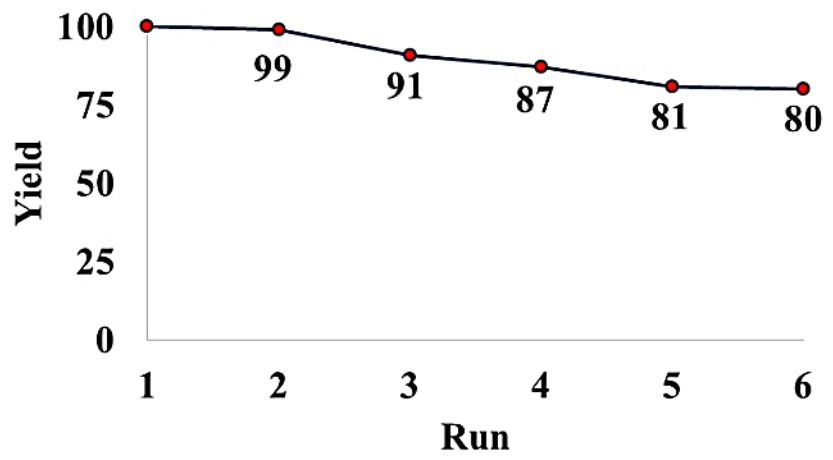

Fig. 9. Recycling of catalyst for the reaction of 4-bromobenzonitrile with phenylboronic acid 
Based on good relation between fluorescence intensity and loading of Pd on Pd@MgO-CQD (Fig. 2), fluorescence emission of each reaction cycle were studied and the amount of leached palladium was detected according the fluorescence value. Results indicated increasing of fluorescence emission of the reaction mixture was started after second run (Fig. 10). By using the obtained equation from Fig. $2(\mathrm{Y}=-703.19 \mathrm{X}+115.08)$ and fluorescence emission $(\mathrm{Y})$ of the each reaction cycle, mmolg ${ }^{-1}$ of Pd (X) on catalyst in each cycle was calculated. Subtracting Pd loading of reused catalyst in each run from Pd loading in fresh catalyst afford amount of leached Pd in each run. From these results we conclude that decreasing of yields after the second run are mainly related to leaching and deactivation of Pd.

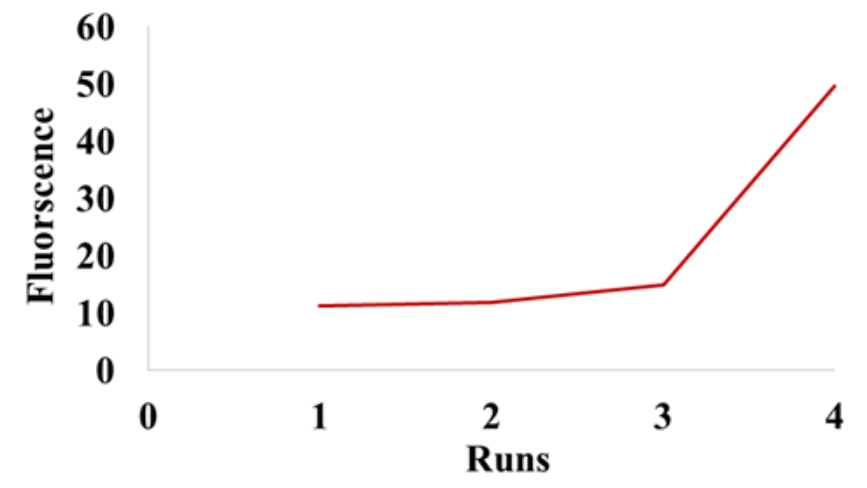

Fig. 10. Fluorescence emissions of each reaction run during recycling processes.

Table 3. Calculation of Pd leaching according to the fluorescence emission of each runs

\begin{tabular}{llll}
\hline Run & Y & X & Pd Leaching $\left(\mathrm{mmolg}^{-1}\right)$ \\
\hline 1 & 11.2 & 0.1477 & $0.148-0.1477=0.0003$
\end{tabular}




$\begin{array}{llll}2 & 11.8 & 0.1468 & 0.148-0.1468=0.0012 \\ 3 & 14.85 & 0.1425 & 0.148-0.1425=0.0055 \\ 4 & 49.65 & 0.0930 & 0.148-0.0930=0.055\end{array}$

The TEM and SEM images of the recycled catalyst showed that Pd@MgO-CQD preserves its structure with little aggregation of the Pd NPs after the fourth run (Fig. 11 and 12). Also, the nitrogen adsorption-desorption isotherms of recycled Pd@MgO-CQD after the fourth run possessed type-III isotherms confirming the stability of the structure during the reaction (Fig. 2, ESI).

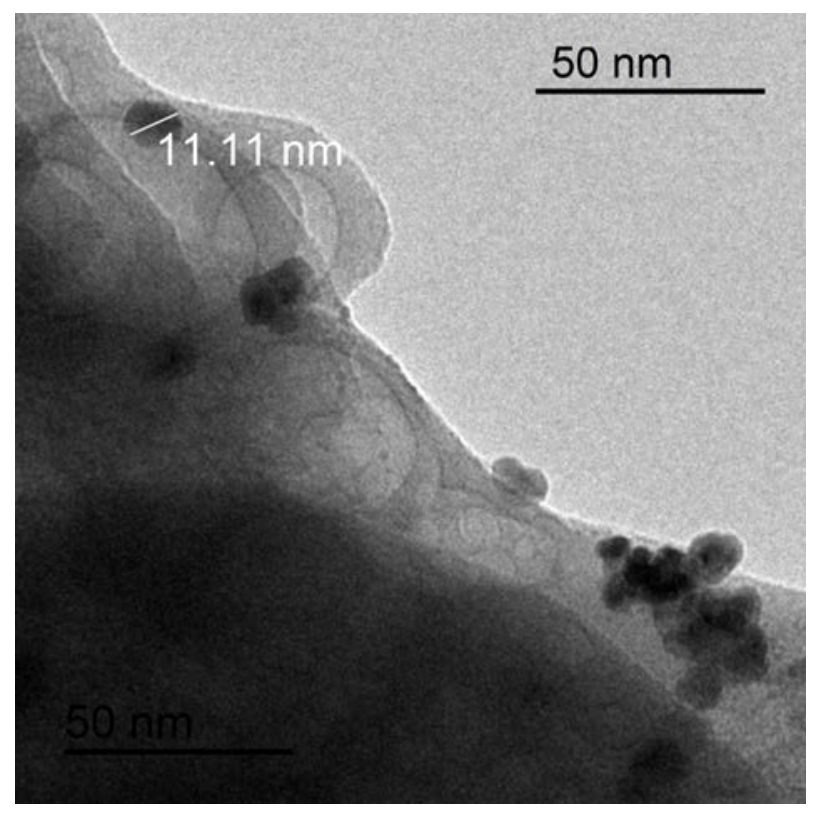

Fig.11. TEM image of the reused catalyst after fourth run 


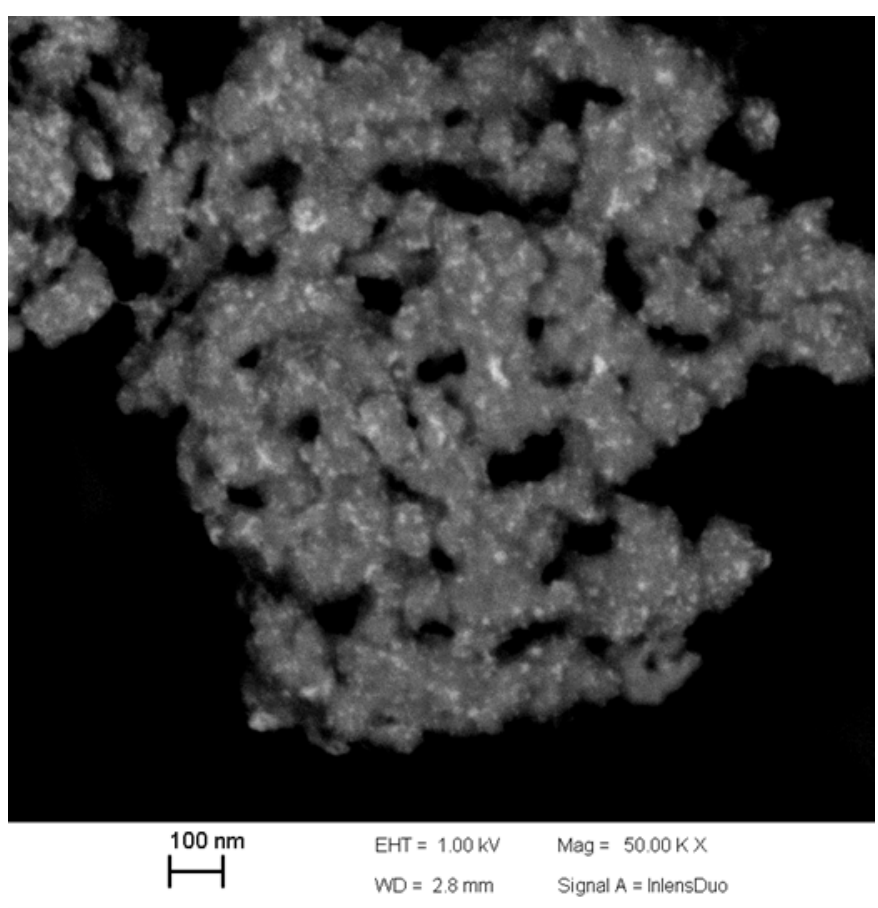

Fig. 12. SEM image of the reused catalyst after fourth run

\section{Conclusions}

An environmentally friendly fluorescence solid support MgO-carbon quantum dots has been easily prepared, which is able to stabilized Pd nanoparticles. This new material Pd@MgO-CQD has shown excellent catalytic efficiency in the Suzuki reaction in water as solvent. Aryl bromides can be cross-coupled with arylboronic acids at room temperature as well as activated aryl chlorides at $80{ }^{\circ} \mathrm{C}$. Remarkable advantages of this stable catalyst are its ability to show fluorescence emission allowing the determination the Pd loading, the recyclability and the aggregation preservation of the Pd Nps.

\section{Acknowledgements}


The authors are grateful to Institute for Advanced Studies in Basic Sciences (IASBS) Research Council and Iran National Science Foundation (INSF-Grant number of 94010666) for support of this work. C. Nájera is also thankful to the Spanish Ministerio de Economia y Competitividad (MINECO) (projects CTQ2013-43446-P and CTQ2014-51912-REDC), FEDER, the Generalitat Valenciana (PROMETEOII/2014/017) and the University of Alicante for financial support.

\section{REFERENCES}

[1] S. K. Sharma, A. Mudhoo, Green Chemistry for Environmental Sustainability, CRC Press, 2010.

[2] P. Anastas, J. C. Warner (Eds.), Green Chemistry: Theory and Practice, Oxford University Press, Oxford, 1998.

[3] P.T. Anastas, M.M. Kirchhoff, Origins, current status, and future challenges of green chemistry, Acc. Chem. Res. 35 (2002) 686-693.

[4] P. J. Dunn, The importance of Green Chemistry in Process Research and Development, Chem. Soc. Rev. 41 (2012) 1452.

[5] M.-O. Simona and C.-J. Li, Green chemistry oriented organic synthesis in water, Chem. Soc. Rev. 41 (2012) 1415.

[6] P. Anastas and N. Eghbali, Green Chemistry: Principles and Practice, Chem. Soc. Rev.39 (2010) 301.

[7] S. Wenda, S. Illner, A. Mell and U. Kragl, Industrial biotechnology-the future of green chemistry, Green Chem. 13 (2011) 3007. 
[8] I. Delidovich and R. Palkovits, Catalytic versus stoichiometric reagents as a key concept for Green Chemistry, Green Chem. 18 (2016) 590.

[9] P. Gupta and A. Mahajan, Green chemistry approaches as sustainable alternatives to conventional strategies in the pharmaceutical industry, RSC Adv. 5 (2015) 26686.

[10] S. G. Newman and K. F. Jensen, The role of flow in green chemistry and engineering, Green Chem. 15 (2013) 1456.

[11] M.-O. Simon and C.-J. Li, Green chemistry oriented organic synthesis in water, Chem. Soc. Rev. 41 (2012) 1415.

[12] Á. Molnár, Palladium-Catalyzed Coupling Reactions: Practical Aspects, Future Developments, Wiley-VCH Verlag, Weinheim, (2013).

[13] Á. Molnár, Efficient, selective, and recyclable palladium catalysts in carbon-carbon coupling reactions, Chem. Rev. 111 (2011) 2251.

[14] A. Fihri, M. Bouhrara, B. Nekoueishahraki, J.-M. Basset, V. Polshettiwar, Nanocatalysts for Suzuki cross-coupling reactions, Chem. Soc. Rev. 40 (2011) 5181.

[15] V. Polshettiwar, A. Decottignies, C. Len, A. Fihri, Suzuki-Miyaura Cross-Coupling Reactions in Aqueous Media: Green and Sustainable Syntheses of Biaryls, ChemSusChem. 3 (2010) 502.

[16] I. P. Beletskaya, A. V. Cheprakov, The Heck Reaction as a Sharpening Stone of Palladium Catalysis, Chem. Rev. 100 (2000) 3009.

[17] S. Kotha, K. Lahiri and D. Kashinath, Recent applications of the Suzuki-Miyaura crosscoupling reaction in organic synthesis, Tetrahedron 58 (2002) 9633. 
[18] M. Pagliaro, V. Pandarus, F. Béland, R. Ciriminna, G. Palmisano, P. Demma Caràa, A new class of heterogeneous Pd catalysts for synthetic organic chemistry, Catal. Sci. Technol. 1 (2011) 736.

[19] C. J. Pink, H.-t. Wong, F. C. Ferreira, A. G. Livingston, Org. Organic Solvent Nanofiltration and Adsorbents; A Hybrid Approach to Achieve Ultra Low Palladium Contamination of Post Coupling Reaction Products, Process Res. Dev.12 (2008) 589.

[20] Y. Yabe, Y. Sawama, Y. Monguch, H. Sajiki, New aspect of chemoselective hydrogenation utilizing heterogeneous palladium catalysts supported by nitrogen- and oxygen-containing macromolecules, Catal. Sci. Technol. 4 (2014) 260.

[21] M. Mora, C. Jiménez-Sanchidrián, J. R. Ruiz, Pain following stroke: a prospective study Curr. Org. Chem. 16 (2012) 1128.

[22] M. Pagliaro, V. Pandarus, R. Ciriminna, F. Béland, P. D. Carà, Heterogeneous versus Homogeneous Palladium Catalysts for Cross-Coupling Reactions, ChemCatChem. 4 (2012) 432.

[23] Ghadiri, W. Chrzanowski and R. Rohanizadeh, Biomedical applications of cationic clay minerals, RSC Adv. 5 (2015) 29467.

[24] S. S. Gupta and K. G. Bhattacharyy, Adsorption of metal ions by clays and inorganic solids, RSC Adv. 4 (2014) 28537.

[25] B. Chen, J. R. G. Evans, H. C. Greenwell, P. Boulet, P. V. Coveney, A. A. Bowden and Andrew Whiting, A critical appraisal of polymer-clay nanocomposites, Chem. Soc. Rev. 37 (2008) 568. 
[26] D. Varade and K. Haraguchi, Novel bimetallic core-shell nanocrystal-clay composites with superior catalytic activities, Chem. Commun. 50 (2014) 3014.

[27] N. M. Julkapli and S. Bagher, Rev Inorg Chem 36 (2015) 1.

[28] K. K. R. Datta, M. Eswaramoorthy and C. N. R. Rao, Water-solubilized aminoclay-metal nanoparticle composites and their novel properties, J. Mater. Chem. 17 (2007) 613.

[29] H. Firouzabadi, N. Iranpoor, A. Ghaderi, M. Gholinejad, S. Rahimi and S. Jokar, Design and synthesis of a new phosphinite-functionalized clay composite for the stabilization of palladium nanoparticles. Application as a recoverable catalyst for $\mathrm{C}-\mathrm{C}$ bond formation reactions, RSC Adv. 4 (2014) 27674.

[30] Y. Du and S. Guo, Chemically doped fluorescent carbon and graphene quantum dots for bioimaging, sensor, catalytic and photoelectronic applications, Nanoscale, 8 (2016) 2532.

[31] S. Y. Lim, W. Shen and Z. Gao, Carbon quantum dots and their applications, Chem. Soc. Rev. 44 (2015) 362.

[32] Y. Wang, A. Hu, Carbon quantum dots: synthesis, properties and applications, J. Mater. Chem. C 2 (2014) 6921.

[33] D. Dey, T. Bhattacharya, B. Majumdar, S. Mandani, B. Sharma, T. K. Sarma, Carbon dot reduced palladium nanoparticles as active catalysts for carbon-carbon bond formation, Dalton Trans. 42 (2013) 13821.

[34] M. Gholinejad, M. Seyedhamzeh, M. Razeghi, C. Najera, and M. Kompany-Zareh, Iron Oxide Nanoparticles Modified with Carbon Quantum Nanodots for the Stabilization of 
Palladium Nanoparticles: An Efficient Catalyst for the Suzuki Reaction in Aqueous Media under Mild Conditions ChemCatChem. 8 (2016) 441.

[35] R. Freeman, T. Finder, I. Willner, Multiplexed analysis of Hg2+ and Ag+ ions by nucleic acid functionalized CdSe/ZnS quantum dots and their use for logic gate operations, Angew. Chem., Int. Ed. 48 (2009) 7818.

[36] M. Li, Q. Wang, X. Shi, L. A. Hornak, N. Wu, Detection of mercury(II) by quantum dot/DNA/gold nanoparticle ensemble based nanosensor via nanometal surface energy transfer, Anal. Chem. 83 (2011) 7061.

[37] Q. Tu, L. Pang, Y. Chen, Y. Zhang, R. Zhang, B. Luc and J. Wang, Effects of surface charges of graphene oxide on neuronal outgrowth and branching Analyst, 139 (2014) 105.

[38] S. Sahu, N. Sinha, S. K. Bhutia, M. Majhi, S. Mohapatra, Luminescent magnetic hollow mesoporous silica nanotheranostics for camptothecin delivery and multimodal imaging J. Mater. Chem. B. 2 (2014) 3799.

[39] J. Sun, Y. Fu, G. He, X. Sun, X. Wang, Catalytic hydrogenation of nitrophenols and nitrotoluenes over a palladium/graphene nanocomposite, Catal. Sci. Technol. 4 (2014) 1742.

[40] M. Gholinejad, M. Razeghi, A. Ghaderi and P. Biji, Palladium supported on phosphinite functionalized $\mathrm{Fe} 3 \mathrm{O} 4$ nanoparticles as a new magnetically separable catalyst for SuzukiMiyaura coupling reactions in aqueous media, Catal. Sci. Technol. 6 (2016) 3117.

[41] M. Gholinejad, N. Jeddi, B. Pullithadathil, Agarose functionalized phosphorus ligand for stabilization of small-sized palladium and copper nanoparticles: efficient heterogeneous catalyst for Sonogashira reaction, Tetrahedron, 72 (2016) 2491. 
[42] M. B. Gawande, P. S. Branco, K. Parghi, J. J. Shrikhande, R. K. Pandey, C. A. A. Ghumman, N. Bundaleski, O. M. N. D. Teodorod and R. V. Jayaram, Synthesis and characterization of versatile $\mathrm{MgO}-\mathrm{ZrO} 2$ mixed metal oxide nanoparticles and their applications, Catal. Sci. Technol. 1 (2011) 1653.

[43] G. Sposito, N. T. Skipper, R. Sutton, S. H. Park, A. K. Soper, J. A. Greathouse, Surface geochemistry of the clay minerals, Proc. Nat. Acad. Sci. 96 (1999) 3358. 